\title{
CURRÍCULO E DOCÊNCIA DE BACHARÉIS NA EDUCACÃO SUPERIOR PRIVADA: DESAFIOS DA PRÁTICA PEDAGÓGICA
}

\author{
CURRÍCULO Y ENSEÑANZA DE LA LICENCIATURA EN EDUCACIÓN SUPERIOR \\ PRIVADA: RETOS DE LA PRÁCTICA PEDAGÓGICA
}

\author{
CURRICULUM AND TEACHING OF BACHELORS IN PRIVATE HIGHER \\ EDUCATION: CHALLENGES OF PEDAGOGICAL PRACTICE
}

Francisco Thiago SILVA ${ }^{1}$

RESUMO: O presente artigo tem por objetivo refletir sobre o campo de atuação docente por parte de bacharéis da educação superior na esfera privada. Tomando a análise documental como esteira metodológica, esta pesquisa exploratória tem caráter qualitativo e bibliográfico, analisa textos clássicos e contemporâneos que tratam dos aspectos da docência na educação superior, além de um breve estado do conhecimento a despeito do que se tem dito academicamente sobre o objeto do artigo, que está estruturado em torno dos seguintes itens: o currículo na docência universitária de instituições privadas, o bacharel atuando como professor, desafios da prática pedagógica na universidade e proposições curriculares: por uma formação pedagógica para bacharéis. Concluímos a especificidade e a centralidade da docência na carreira dos professores de instituições de ensino superior, ao mesmo tempo problematizado os meandros, as limitações e as possibilidades que se fazem presentes na esfera privada. Espaço que não pode e nem deve ser apenas de pesquisa e aplicação de teorias externas a ele, antes, deve possuir autonomia e construir elementos que possibilitem o pleno desenvolvimento de suas demandas, passando, por suposto, pela prática da formação continuada de seus professores, que independentemente se licenciados ou bacharéis têm a responsabilidade coletiva de fazer a universidade cumprir o seu papel: produzir conhecimento.

PALAVRAS-CHAVE: Currículo. Docência. Bacharéis. Educação superior.

RESUMEN: Este artículo pretende reflejar en el campo docente por alumnos de la educación superior en el ámbito privado. Tomando el análisis documental como estera metodológica, esta investigación tiene cualitativa y analiza textos clásicos de carácter bibliográfico y contemporánea tratar aspectos de la enseñanza en educación superior, además a un breve estado de conocimiento a pesar de la que se ha dicho sobre el objeto de este artículo académico, que se estructura alrededor de los siguientes elementos: el plan de estudios en docencia universitaria de las instituciones privadas, la carrera como maestro, desafíos de la práctica pedagógica en la Universidad y las proposiciones los planes de estudios: formación pedagógica para licenciados. Concluimos que la especificidad y la centralidad de la enseñanza en la carrera de profesores de instituciones de educación

${ }^{1}$ Universidade de Brasília (UNB), Brasília - DF - Brasil. Doutor e Mestre em Educação e Currículo. Licenciado em História e Pedagogia. Professor da SEDF e do Centro Universitário Projeção. Líder do grupo de pesquisa: "Currículo e Interdisciplinaridade na Formação Docente" (CNPQ). ORCID: http://orcid.org/0000-0002-69982757. E-mail: fthiago2002@yahoo.com.br

RIAEE - Revista Ibero-Americana de Estudos em Educação, Araraquara, v. 14, n. 4, p. 2189-2204, out./dez., 2019. e-ISSN: 1982-5587. DOI: https://doi.org/10.21723/riaee.v14i4.10866 
superior y, al mismo tiempo problematiza las complejidades, las limitaciones y posibilidades que están presentes en la esfera privada. Espacio que no puede y no debe ser sólo para investigación y aplicación de teorías externas primero debe tener autonomía y construir elementos que hacen posible el desarrollo integral de sus demandas, pasando por todos los medios, la práctica de la educación continua de sus maestros, Independientemente, si graduados o alumnos tienen la responsabilidad colectiva para hacer la Universidad cumplir con su función: producir conocimiento.

PALABRAS CLAVE: Plan de estudios. Enseñanza. Antiguos alumnos. Educación superior.

ABSTRACT: This article aims to reflect on the field teaching by alumni of higher education in the private sphere. Taking the documentary analysis as methodological mat, this exploratory research has qualitative and analyses bibliographic character classic texts and contemporary dealing with aspects of teaching in higher education, in addition to a brief State of knowledge despite the that has been said about the object of this academic article, which is structured around the following items: the curriculum in university teaching of private institutions, the Bachelor's degree acting as teacher, challenges of pedagogical practice in University and propositions curricula: pedagogical training for Bachelors. We conclude that the specificity and centrality of teaching in career of teachers of institutions of higher education and, at the same time problematized the intricacies, the limitations and possibilities that are present in the private sphere. Space that can't and shouldn't be just for research and application of external theories he first must have autonomy and build elements that make possible the full development of their demands, passing by all means, the practice of continuing education from their teachers, Regardless, if graduates or alumni have the collective responsibility to make the University fulfill your role: produce knowledge.

KEYWORDS: Curriculum. Teaching. Alumni. Higher education.

\section{Primeiras palavras}

Os desafios impostos à prática docente no nível da Educação Superior Privada no Brasil, especificamente na graduação, comportam inúmeros itens que, embora sejam cotidianos na esfera de atuação dos professores desta etapa do nível superior, pouco são discutidos, e se são, muitas reflexões, por vezes pertinentes, não conseguem apresentar saídas para os vários impasses vividos no ambiente universitário, cercado de contradições e desafios.

Escolhemos o campo do currículo com vistas a propor caminhos plausíveis que tentam responder, ou mesmo direcionar, nossas atitudes gerenciais e pedagógicas que objetivem garantir uma prática docente segura que atenda ao perfil de saída ${ }^{2}$ dos estudantes.

${ }^{2} \mathrm{O}$ termo é específico da área curricular e refere-se ao conjunto de predicados prescritos e exigidos ao longo de qualquer processo formativo, sobretudo quando a esfera da prática curricular é a graduação. Diante de uma teoria crítica de currículo (APLLE, 2006) afirma-se que é este perfil quem determina o funcionamento de todo o "sistema curricular" (SACRISTÁN, 2000). 
É preciso lembrar, todavia, que a opção por investigar a prática docente de bacharéis se dá pelo crescimento (Em 2016, 34.366 cursos de graduação foram ofertados em 2.407 Instituições de Educação Superior - IES, no Brasil, para um total de 8.052.254 estudantes matriculados ${ }^{3}$ ) dos cursos de graduação, onde esses profissionais atuam, o que não significa que a docência de licenciados esteja devidamente alinhada com o que se espera academicamente ou mesmo que os debates nesta seara sejam plácidos.

Tomando a análise documental como esteira metodológica, esta pesquisa exploratória tem caráter qualitativo e bibliográfico, analisa textos que tratam dos aspectos da docência na educação superior, além de um breve estado do conhecimento a despeito do que se tem dito academicamente sobre o objeto do presente artigo, que está estruturado em torno dos seguintes itens: o currículo na docência universitária de instituições privadas, o bacharel atuando como professor, desafios da prática pedagógica na universidade e proposições curriculares: por uma formação pedagógica para bacharéis.

\section{O currículo na docência universitária de instituições privadas}

O campo dos estudos curriculares tem encontrado terreno fértil para ampliar seu leque de discussões no Brasil, embora nos últimos anos as grandes políticas para a área têm se fundamentado em debates pouco democráticos, de caráter impositivo e verticalizado, fazendo a legislação curricular retroceder nos tímidos avanços que alcançou nas duas décadas anteriores. Como por exemplo, a "reforma da caneta", para Borges e Silva (2016): as mudanças impostas ao ensino médio nacional em nada representam os debates pedagógicos ocorridos no ambiente universitário e escolar. Tem-se ainda a fantasiosa "escola sem partido", que na verdade é a expressão máxima no controle e da regulação do trabalho docente sob a égide de uma visão equivocada do pensamento religioso aplicada ao ensino, que busca, dentre outras coisas, expropriar a autonomia intelectual dos professores.

Em sua gênese, a universidade como espaço universal de produção de novos conhecimentos humanos esteve ligada à prosperidade social e econômica dos países que abriram caminho para este nível da educação formal. Desde a Idade Média, as instituições de ensino superior foram palco de grandes debates, mesmo na fase inicial em que eram sustentadas e orientadas pela fé católica romana.

3 Disponível em: http://portal.inep.gov.br/artigo/-/asset_publisher/B4AQV9zFY7Bv/content/mec-e-inepdivulgam-dados-do-censo-da-educacao-superior-2016/21206. Acesso em: 26 out. 2017. 
No período pós-revoluções, o velho continente experimentou inúmeras transformações, nem todas positivas, o modo de produção capitalista e o mundo fabril aplicaram a países como Inglaterra e Alemanha um desenvolvimento econômico jamais visto, mas também à custa de condições de trabalho sub-humanos àqueles que, de fato, vendem sua força de trabalho para sobreviver.

Quando a Família Real portuguesa chega ao Brasil, refugiando-se dos tentáculos da política expansionista de Napoleão Bonaparte, a então colônia, sobretudo a sua capital, o Rio de Janeiro experimentou mudanças radicais, dadas as circunstâncias históricas em que a corte chega a sua mais rica colônia. Entre 1808 e 1822 foram criados alguns cursos superiores - não era intenção da metrópole oferecer espaços de reflexão para seus colonos, como o da universidade, já que os mesmos poderiam ser fomento para os movimentos independentistas , como medicina, direito e engenharia, para ocupar os professores universitários portugueses que agora habitavam o Brasil:

Os cursos de Cirurgia na Bahia, Cirurgia e Anatomia no Rio de Janeiro, ambos datados de 1808; a Academia Real da Marinha e Real Militar (1810); a Escola de Agricultura (1812); a Escola Real de Ciências, Artes e Ofícios (1816); o curso de Química (1817), de Desenho Industrial (1818) e posteriormente os cursos jurídicos (Convento de São Paulo e Mosteiro de São Bento, em Olinda) e a primeira Faculdade de Filosofia do Brasil, fundada em 1908 no mosteiro Beneditino de São Paulo, podem ser considerados como os primeiros passos para a formação de uma consciência universitária no Brasil (BRITO; CUNHA, 2009, p. 48).

Mas estes cursos de bacharelado eram isolados, com intuito de formar a elite imperial, além de não haver ainda nestas terras intenção de criar uma universidade, nos moldes modernos que a Europa tinha imprimido ao resto do mundo, inclusive na América do Sul, que praticamente tinha uma universidade em cada colônia ou ex-colônia espanhola, como aponta Teixeira (1999, p. 297):

O Brasil constitui uma exceção na América Latina: enquanto a Espanha espalhou Universidades pelas suas colônias - eram 26 ou 27 ao tempo da independência -, Portugal, fora dos colégios reais dos jesuítas, nos deixou limitados às Universidades da Metrópole: Coimbra e Évora.

Apenas no período da República Velha o Brasil reuniu esforços e criou suas primeiras universidades, baseadas no modelo francês, alemão e norte-americano (BRITO; CUNHA, 2009), alimentado pela premissa de que "A falta de investimento nas universidades torna extremamente difícil para fornecer serviços de assistência básica à população" (MCCOWAN; SCHENDEL, 2015, p. 37). 
Com relação ao campo privado, algumas iniciativas “[...] ocorreram, como a criação da Universidade de Manaus (1909), São Paulo (1911), Curitiba (1912), que posteriormente foram extintas por não terem o apoio político e financeiro do Governo Federal" (BRITO; CUNHA, 2009, p. 49).

O papel da igreja católica, segundo Martins (2002, p. 5) foi primordial para consolidar o ensino superior para a iniciativa privada:

O período de 1931 a 1945 caracterizou-se por intensa disputa entre lideranças laicas e católicas pelo controle da educação. Em troca do apoio ao novo regime, o governo ofereceu à Igreja a introdução do ensino religioso facultativo no ciclo básico, o que de fato ocorreu a partir de 1931. As ambições da Igreja Católica eram maiores e culminou com a iniciativa da criação das suas próprias universidades na década seguinte.

É importante levantar dados que demonstram que desde sua gênese, as Instituições de Ensino Superior apresentam público-cativo, e até os dias atuais, como apresentamos anteriormente, se mantêm absolutas como lócus majoritário de formação de profissionais:

Em 1933, ano em que se passou a contar com as primeiras estatísticas sobre educação, o setor privado respondia por $64,4 \%$ dos estabelecimentos e 43,7\% das matrículas do ensino superior, [...] No período 1940-1960 a população do país passou de 41,2 milhões para 70 milhões (crescimento de $70 \%$ ), enquanto que as matrículas no ensino superior triplicaram. Em 1960, existiam 226.218 universitários (dos quais 93.202 eram do setor privado) A pressão de demanda levou a uma expansão extraordinária no ensino superior no período 1960-1980, com o número de matrículas saltando de aproximadamente 200.000 para 1,4 milhão, 3/4 partes do acréscimo atendidas pela iniciativa privada. Em finais da década de 1970 o setor privado já respondia por $62,3 \%$ das matrículas, e em 1994 por 69\% (MARTINS, 2002, p. 5).

Não restam dúvidas de que a universidade mantém e desenvolve as tradições culturais de uma nação propondo investigações, pesquisas e inovações que beneficiam inúmeras pessoas. Mas a questão do acesso, da permanência e da aquisição de diplomas nesta esfera da educação ainda permanece como um imbróglio em nosso país, infelizmente ainda existe um fosso entre a universidade pública e privada no que diz respeito às condições de ingresso e de atuação docente, que é justamente nossa preocupação central neste artigo.

Inúmeras pesquisas já debateram a situação estudantil nos cursos superiores, como é o caso de Junior, Sousa, Azevedo e Chaves (2015). Nosso olhar se detém na necessidade de discutir um programa de formação pedagógica específica para professores bacharéis, isso se dá, sobretudo, porque, mesmo sendo uma preocupação nas instituições públicas, os números não negam que a esfera privada tem se apropriado das ofertas de cursos em larga escala, o que 
tem ocasionado também uma enorme diversidade de campos profissionais de atuação do magistério em nível superior.

Segundo dados do INEP, em 2016, quase 3 milhões de alunos ingressaram em cursos de educação superior de graduação. Desse total, 82,3\% em instituições privadas, o que confirma nosso pressuposto anterior, além disso, nos valemos das advertências de Sousa (2013) e Gatti; Barreto (2009): nos últimos anos, o Estado optou por minimizar os investimentos da esfera pública de educação superior e supervalorizar e estimular investimentos de expansão no setor.

Queremos avançar para além da crítica pela crítica, que muitos autores do campo investem ao afirmarem que o ensino nas instituições privadas é frágil e que a pesquisa é coadjuvante; não iremos investigar pesquisa e extensão, mas a docência nestes espaços, ao que tudo indica um assunto que também é campo minado nas universidades mantidas pelo poder público. Tais argumentos pouco fazem a retórica avançar. É necessário que haja diálogos entre os profissionais do magistério superior, de todos os espaços, porque os que exercem atividade laboral no serviço público têm muito a conversar com os colegas das empresas privadas, esses últimos são sujeitos históricos e igualmente professores que precisam ser compreendidos, para além de meros objetos de estudo.

Sobre o campo curricular é preciso situá-lo numa moldura mais ampla como sendo uma trincheira na arena educacional, seja como "documento de identidade" (SILVA, 2011), como "território contestado" (MOREIRA; SILVA, 2011) ou ainda como espaço de disputas ideológicas (APPLE, 2006); currículo, em sua constituição mais simplista, se é que existe esta possibilidade, pode ser compreendido como a forma de organizar o conhecimento. E é neste conceito que reside o papel central dos professores como protagonistas do processo de criação, execução e avaliação de todo o "sistema curricular", como defende também Sacristán (2000), todavia, inúmeros fatores estruturais, teóricos e pedagógicos levam muitos docentes da esfera privada, inclusive os licenciados, a atuarem como mero reprodutor das propostas curriculares aprovadas nas instâncias superiores dessas instituições de ensino. Salvo algumas faculdades, centros universitários e universidades que excepcionalmente investem em debates na formação continuada de seus profissionais do ensino no âmbito do campo curricular.

Se para os professores universitários que atuam na formação de profissionais ligados ao magistério - e que em tese conhecem alguma face do campo curricular - o debate curricular é complexo, para os docentes bacharéis descortinar o centro gravitacional de sua própria prática, que para muitos nem é pedagógica, torna-se um desafio hercúleo para as 
instituições de ensino superior, já que a maioria contrata seu quadro docente observando-se fria e puramente a titulação de mestrado ou doutorado, cumprindo o que prevê a própria Lei de Diretrizes e Bases da Educação Nacional, LDB, Lei nº 9394/96.

Quando afirmamos ser o currículo a coluna dorsal que orienta a Organização do Trabalho Pedagógico - OTP, nos apropriamos do conceito de Freitas (1995), que apresenta o próprio currículo (o que ensinar), a didática (como ensinar) e a avaliação (como evidenciar a aprendizagem) como sendo o tripé que sustenta a prática pedagógica de todos os professores.

Não temos a intenção de ventilar um debate mais amplo sobre teoria e prática curricular, apenas de chamar a atenção para a necessidade de apropriação de leituras do campo como sendo a largada para pensar uma prática pedagógica na universidade que seja mais eficiente, e que traga a pesquisa e a extensão centradas do ensino.

\section{O bacharel atuando como professor}

Sabemos que a formação inicial de professores em nível de graduação não é suficiente para garantir uma sólida atuação na educação básica, tampouco no nível superior, e mais difícil ainda quando esta etapa inicial de formação dos formadores é o bacharelado, que tem finalidades muito distintas da docência.

Ocorre que o próprio bacharelado necessita da presença de docentes e o dilema se alicerça quando os cursos têm dificuldades de reafirmar que seus professores são bacharéis de formação, mas inicialmente são docentes-bacharéis, isso se dá, em parte, pelo desprestígio pelo qual a carreira docente tem no Brasil, ainda que um profissional externo à licenciatura atue como professor, mesmo que seja na educação superior, ele se autodenomina como um jurista que dá aula, um médico que também ministra o ensino ou ainda um engenheiro que está professor. Sobre isso, Demo (2015) enfatiza que

Em termos concretos, as melhores universidades são de pesquisa, mas nem sempre, sendo de pesquisa, oferecem boa aprendizagem. Quem nelas estuda, ao final, precisa pesquisar, produzir, elaborar. Aula é secundária [...] O que move a educação superior é a rebeldia da pesquisa, não aula, prova, reprodução, xerox (p. 11).

Se pensarmos que a aula é coadjuvante no universo do ensino superior, mas pensarmos nessa afirmação partindo da esfera pública, isso já não se aplica às iniciativas privadas, mesmo as que alçam o status de centros universitários ou até universidades. Nesses espaços, o 
centro da OTP ainda é o ensino e, portanto, a aula, não se trata de debater aqui se é mais importante um ou outro elemento do tripé da educação superior, a saber: ensino, pesquisa ou extensão, mas problematizar e propor saídas para que ao menos, o item aula (docência) seja objeto de discussão nos espaços privados de formação. Uma vez que isso seja pensado coletivamente, espera-se que a pesquisa e a extensão passem a coexistir de forma dinâmica e intencional.

Mas é preciso, ainda, problematizar sobre qual nicho de atuação este professor universitário trabalha. Na última década o mercado financeiro trouxe o ramo educacional como sendo uma excelente oportunidade de investimento, com parceira pública e privada, não é à toa que alguns grupos educacionais se tornaram grandes investidores em bolsas de valores ao ponto de redes privadas de ensino superior possuírem até duzentos mil estudantes matriculados, como apontam Machado e Paixão (2015):

As mudanças ocorridas no ensino superior brasileiro privilegiaram a iniciativa privada e uma maior atuação mercadológica no setor educacional. Ficou claro na LDB no 9394/96 que o mercado é um bom empreendedor e que a privatização deve ser adotada. Esse ideal colaborou para a criação de um mercado educacional (p. 130).

Diante deste cenário as mudanças na rotina pedagógica dos profissionais destas instituições também se alteraram substancialmente nos últimos vinte anos, conforme enumera Suanno (2015): flexibilização do trabalho e acúmulo excessivo de carga horária para garantir renda, submissão de constantes processo de avaliação de desempenho que interferem diretamente no valor da remuneração, intensificação do próprio trabalho docente (DAL ROSSO, 2008). Esse cenário criou a chamada "burguesia de serviço", conforme Maués (2015), um grupo social que ascendeu economicamente com a mercantilização e privatização da educação superior com o aval das políticas públicas, com isso não é de se estranhar que a universidade tem sofrido radicais mudanças que,

[...] alteram a cultura acadêmica, a identidade institucional, seus objetivos (missões), o que está trazendo consequências para o papel que o profissional da educação deve desempenhar, modificando o fazer acadêmico-pedagógico e acarretando um processo de intensificação, precarização e adoecimento para os docentes (p. 207).

No mesmo texto a autora (idem) denuncia que esta rotina desgastante trouxe um novo perfil para o docente da "nova" Educação Superior, segundo a pesquisadora, “[...] o professor passa a ser um empreendedor” (p. 214), regido pelas regras rígidas e mercadológicas da Coordenação de Aperfeiçoamento de Pessoal de Nível Superior - CAPES e do Conselho 
Nacional de Desenvolvimento Científico e Tecnológico - CNPQ, tendo ainda que cultivar com muito adubo seu currículo lattes, já que ele é o cartão postal que serve como propaganda pública da instituição que o contratou. Assim, o professor pensa, planeja, executa e avalia seu próprio processo pedagógico e se submete a condições de trabalho e a uma carga horária desumana, e ainda deve escrever e publicar em notórios espaços de divulgação acadêmicocientífico. Fora isso, ele ainda participa de inúmeras reuniões de pesquisa, de colegiado, de departamento, de comissões, de coordenação, de extensão e ainda de conselhos superiores.

\section{Desafios da prática pedagógica na universidade}

Talvez um ponto central entre os desafios enfrentados pelos professores universitários do bacharelado seja o reconhecimento de que este nível de ensino tem particularidades teóricas, pedagógicas e estéticas específicas que não são objeto de estudo de sua área de formação inicial, ora, se nem o professor da educação básica se torna automaticamente docente da universidade, quanto mais os profissionais que não estudam a docência em seu início de vida acadêmica, mas encontram espaço central no campo educacional das licenciaturas e nos programas de pós-graduação lato e stricto sensu. A premissa de que se dorme pesquisador e acorda professor

[...] é equivocada. Ela desconsidera um elemento central para o processo de formação continuada: não existe professor calouro. Um docente com doutorado, por exemplo, ao inicia sua carreira como docente possui, pelo menos, 21 anos de escolarização entre o ensino fundamental, médio, curso de graduação, mestrado e o próprio doutorado. Durante esses 21 anos, além dos conteúdos de várias matérias que foram vistos, aprendidos e desprezados, um conteúdo contínuo e construído de forma silenciosa e na maioria dos casos com pouca reflexão: o conteúdo sobre como ser docente (MARIZ; NETO, 2015, p. 151).

Pimenta e Anastasiou (2010) ponderam que, infelizmente, a docência é quase inexistente no percurso acadêmico desses professores mestres e doutores em suas áreas de formação inicial do bacharelado, isso faz com que este pseudo-professor aprenda

[...] a sê-lo mediante um processo de socialização de prática intuitiva, autodidata ou [...] seguindo a rotina dos "outros". Isso se explica, sem dúvida, devido a inexistência de uma formação específica como professor universitário. Nesse processo joga um papel mais ou menos importante sua própria experiência como aluno, o modelo de ensino que predomina no sistema universitário e as reações de seus alunos, embora não há que se descartar a capacidade autodidata do professorado, mas ela é insuficiente (p. 36). 
Portanto, o ensino como objeto de estudo no percurso acadêmico deste professor universitário foi subsumido, ele passa, então, a reproduzir comportamentos de seus professores e de seus colegas, mais experientes, “[...] o professor do ensino superior aprende a docência de acordo com a socialização ora intuitiva e autodidata ora seguindo a rotina de outros professores, confluindo com sua própria experiência enquanto aluno" (RECHE; VASCONCELLOS, 2014, p. 7), o que pode gerar uma prática pedagógica irresponsável, improvisada e que pouco contribui para a formação esperada nos cursos, já que, segundo Veiga (2016), não basta ser um renomado pesquisador ou ainda possuir uma alta titulação, como doutorado e pós-doutorado, e não conseguir exercer a docência com eficiência.

Em pesquisa recente, Reche e Vasconcellos (2014) demonstram que a ampla maioria dos docentes que são bacharéis em instituições de ensino privadas tem a docência como atividade completiva de renda, ainda assim muitos gostariam de ter a docência como ocupação trabalhista central, mas apontam as fragilidades de atuar nas recentes condições, que servem de argumentos para manter-se apenas como horistas nessas instituições. Eis os argumentos:

- Baixo salário;

- Excesso de trabalho;

- Necessidade de tempo extra de trabalho.;

- Pressão para o cumprimento de prazos e atividades;

- Falta de incentivo à profissionalização;

- Falta de reconhecimento da profissão, além da;

- Desmotivação e despreparo dos colegas docentes.

Ser professor na educação superior significa lidar uma complexidade de público, de conhecimentos e de demandas que exigem domínio plural de inúmeras áreas que não podem ser reduzidas apenas à de formação inicial deste professor. Dessa maneira, o profissional do ensino superior competente é aquele que, além do pleno domínio específico de sua formação, articula com maestria os conhecimentos didático-pedagógicos que são próprios desta esfera de atuação e que se afunilam com o objeto de estudo próprio de suas disciplinas.

Afirmamos anteriormente que os cursos de mestrado e de doutorado pelo país não se preocupam muito com a formação de seus futuros quadros docentes, nem mesmo quando são programas de educação ou de ensino. Isso ocorre, em parte, porque muitos professores são 
incentivados em seus próprios departamentos a participar de cursos e eventos com ênfase na pesquisa; para Fernandes (2001), o desempenho de muitos professores universitários é metrificado por sua produção científica na forma de palestras, artigos, capítulos de livro, etc. A prática pedagógica permanece no limbo.

Essa mesma prática pedagógica precisa ser desvelada, já que, segundo Freire e Carneiro (2012), em pesquisa sobre dar aula na universidade, revelaram que boa parte dos professores que são bacharéis concebem a prática “[...] apenas como a transmissão mecânica de conhecimentos, distanciando-se muito da possibilidade de ser um espaço para os alunos de compreensão genuína de seu campo de atuação" (p. 3.853).

\section{Proposições curriculares: por uma formação pedagógica para bacharéis}

Não restam dúvidas de que é urgente que se apresente uma formação específica para bacharéis: "[...] a fim de proporcionar, através de práticas inovadoras, desafiadoras, um ensino voltado não apenas ao acúmulo e reprodução de conhecimentos, mas à aquisição e desenvolvimento de competências e saberes de suas respectivas áreas de formação e de atuação" (SILVA; GONZAGA, 2016, p. 3).

É papel, portanto, da própria instituição de ensino fomentar políticas próprias que propiciem o estudo e a formulação de práticas inovadoras no âmbito da docência universitária. Infelizmente não existem modelos pré-fabricados para este fim, cada instituição formativa deverá encontrar sua fórmula, ao considerar sua área social de atuação e público atendido, além dos cursos e professores que possui. É exercer com serenidade e segurança sua autonomia financeira, administrativa e pedagógica, fugindo do pragmatismo irresponsável.

Não quisemos neste texto criticar num vazio irresponsável o modo de trabalho na esfera privada do ensino superior, ao contrário, a intenção foi problematizar, sem hipocrisia, este nicho trabalhista, e apresentar alguns caminhos que poderão e deverão ser ampliados em cada instituição de ensino, que mesmo parecendo uma empresa apenas, lida com o processo complexo da educação que, de fato, não pode reduzir-se a mero espaço mercadológico de transmissão de conteúdo. Vale a pena refletirmos a partir da citação abaixo:

[...] é necessário começar por um esforço intencional e sistemático para responsabilizar a instituição pela formação pedagógica de seus professores, ao mesmo tempo investindo na produção de um conhecimento sobre essa formação e a diferença que ela pode fazer nos processos de ensinar e aprender para formar cidadãos deste país - uma grande tarefa! (ORO; BASTOS, 2012, p. 9). 
Propor uma formação pedagógica específica para bacharéis é ir à contramão da crença explicitada por Pachane (2009), “[...] da cultura da negação da necessidade de formação pedagógica para a atuação docente no ensino superior” (p. 38). É preciso fomentar espaços coletivos para debater esta iminente necessidade e buscar influenciar a criação de políticas de regulamentação, que intentem incentivar e valorizar espaços acadêmicos de formação continuada para profissionais que não precisam, mas não puderam estudar a lógica da Organização do Trabalho Pedagógico, ligada a assuntos como os elencados no quadro ${ }^{4}$ abaixo:

\section{Quadro 1 - Organização do Trabalho Pedagógico}

- História da Educação Superior no Brasil.

- A relação entre didática e prática pedagógica.

- Os conceitos de Educação, Pedagogia, Didática, Ensino e Instrução.

- As principais correntes e tendências do pensamento pedagógico moderno.

- Teorias e Práticas de currículo.

- Integração e Interdisciplinaridade.

- Diferentes concepções de avaliação.

- Os diferentes tipos de planejamento educacional.

- Os componentes do processo de ensino: conteúdo, objetivo, métodos e técnicas de ensino.

- A construção da aula na universidade.

Fonte: Elaboração própria dos autores

Retomamos o campo do currículo agora para reafirmamos que o seu pleno domínio pelas esferas da gestão e da coordenação pedagógica dos cursos que abrigam essa diversidade de docentes poderá garantir uma formação e uma atuação sólidas por parte desses profissionais. Para tanto, apontamos abaixo uma série de predicados que devem formar o perfil de saída e de atuação dos professores universitários, mais uma vez ponderando que são apenas reflexões iniciais, como já afirmamos anteriormente neste mesmo texto, cada instituição de ensino é quem deve planejar e executar seu próprio programa de formação continuada. Por fim, são essas ações esperadas por parte dos professores do ensino superior:

- Extrapolar o exercício da docência para além da mera reprodução do ensino que se recebeu durante a formação;

- Reconhecer-se como professor, ao menos no espaço profissional da universidade;

- Compreender a lógica da Organização do Trabalho Pedagógico - OTP no que se refere ao currículo, à didática e à avaliação;

${ }^{4}$ A intenção deste texto não é de ser prescritivo, mas um norteador de futuras proposições de formação continuada e permanente na universidade que atendam especificamente este público: bacharéis que atuam como professores. 
- Relacionar e aplicar os saberes específicos com os de caráter didático-pedagógico;

- Utilizar as novas tecnologias sob uma visão pedagógica aplicadas ao objeto de estudo de suas disciplinas;

- Lidar e relacionar-se com os documentos prescritivos de cunho pedagógico que devem situar a prática docente: Projeto de Desenvolvimento Institucional - PDI, Projeto Pedagógico de Curso - PPC, Plano de Ensino e o Plano de Aula.

Este último item é o mais importante e sintetiza a nossa defesa pela centralidade dos estudos curriculares. Talvez um dos momentos mais tensos da atuação dos professores universitários, que são bacharéis e até de alguns licenciados, é estabelecer uma lógica didática que garanta a harmoniosa relação entre os conteúdos e temas que são importantes para aquela área em forma de planejamentos, os mesmos têm uma lógica de construção que é próprio do campo pedagógico e devem expressar uma correta relação entre teoria e prática docente.

Ao mesmo tempo as demandas da profissão do futuro formado e os objetivos gerais e específicos que são anunciados pela instituição de ensino, o que inclui o uso das bibliografias presentes nos documentos, e a adesão aos programas próprios da universidade e da natureza do curso não podem se perder na OTP.

A pretexto de não encerrar essa profícua discussão, uma proposição futura de pesquisa é escrever sobre como proceder com a relação entre os diferentes níveis do planejamento e do currículo para a educação superior. Por enquanto, nos damos por satisfeitos em ter demonstrado a especificidade e a centralidade da docência na carreira dos professores de instituições de ensino superior e, ao mesmo tempo problematizado os meandros, as limitações e as possibilidades que se fazem presentes na esfera privada. Espaço que não pode e nem deve ser apenas de pesquisa e aplicação de teorias externos a ele, antes, deve possuir autonomia e construir elementos que possibilitem o pleno desenvolvimento de suas demandas, passando, por suposto, pela prática da formação continuada de seus professores, que independentemente se licenciados ou bacharéis têm a responsabilidade coletiva de fazer a universidade cumprir o seu papel: produzir conhecimento.

\section{Reflexões finais}

Percebemos ao longo do texto que a docência universitária é complexa e dinâmica por que sua natureza é interativa, não podendo ser secundarizada em detrimento da pesquisa ou da extensão. 
A preocupação das instituições de ensino de caráter privado deve ser com a manutenção de seus serviços a pleno vapor. E neste caso, o "produto" é a educação, que não pode ser mera mercadoria, ainda acreditamos que ela seja um direito fundamental de todo sujeito.

Ao longo do texto apontamos caminhos que passam pela capacidade da instituição em exercer sua autonomia e tomar as rédeas de formação continuada de seus docentes, não abrindo mão de criar programas específicos para tal fim. Nossa sugestão é que o campo do currículo seja central, pois, somente com o pleno domínio dos diferentes atores sociais da universidade da lógica do "sistema curricular" (SACRISTÁN, 2000) é que será possível garantir a função específica da universidade no século XXI.

Por fim, nossa preocupação em abordar a atuação dos bacharéis se dá pelo elevado número de professores desse nicho e pela pouca pesquisa que é feita sobre este objeto de estudo.

\section{REFERÊNCIAS}

APPLE, M. Ideologia e currículo. Porto Alegre: Artes Médicas, 2006.

BENEDITO, V. et al. La formación universitaria a debate. Barcelona: Universidade de Barcelona, 1995.

BORGES, L. F. F.; SILVA, F. T. A Reforma Da Caneta: Reflexões Curriculares Acerca Do Ensino Médio Profissional No Brasil Atual. Revista Binacional Brasil Argentina: Diálogo entre às Ciências, v. 5, p. 87-100, 2016.

BRITO, T. T. R.; CUNHA, A. M. de O. Revisitando a História da Universidade no Brasil: política de criação, autonomia e docência APRENDER - Cad. de Filosofia e Psic. da Educação. Vitória da Conquista, Ano VII, n. 12, p. 43-63, 2009.

DAL ROSSO, S. Mais trabalho!: a intensidade do labor na sociedade contemporânea. São Paulo: Boitempo. 2008.

DEMO, P. Prefácio. In: GUIMARÃES-IOSIF, R.; ZARDO, S. P.; SANTOS, A. V. dos (Orgs.). Educação Superior: conjunturas, políticas e perspectivas. Brasília: Líber Livro, 2015.

FERNANDES, C. M. B. Docência universitária e os desafios da formação pedagógica.

Revista Interface - Comunicação, Saúde, Educação, v. 9, Ago., 2001.

FREIRE, L. de A.; CARNEIRO, I. M. S. P. Reflexões Sobre O Trabalho Docente Do Professor Bacharel: Perspectivas Para A Formação Continuada. Junqueira \& Marin Editores Livro 3. XVI ENDIPE - Encontro Nacional de Didática e Práticas de Ensino - UNICAMP - Campinas - 2012 
FREITAS, L. C. Crítica da organização do trabalho pedagógico e da didática. Campinas: SP, Papirus, 1995.

GATTI, B. A.; BARRETTO, E. S. de S. Professores do Brasil: impasses e desafios. Brasília: Unesco, 2009.

SILVA JÚNIOR, J. dos R.; SOUSA, J. V. de; AZEVEDO, M. L. N. de; CHAVES, V. L. J. (Orgs.). Educação Superior: Internacionalização, mercantilização e repercussões em um campo de disputas. Belo Horizonte, MG: Fino Traço, 2015.

MACHADO, J. L.; PAIXÃO, D. L. L. A educação superior e as políticas de formação para professores da educação básica. In: GUIMARÃES-IOSIF, R.; ZARDO, S. P.; SANTOS, A. V. dos (Orgs.). Educação Superior: conjunturas, políticas e perspectivas. Brasília: Líber Livro, 2015.

MARIZ, R. S.; NETO, U. G. da S. Educação superior no Brasil e o movimento pendular entre a casa do saber para poucos e a fábrica de diploma para muitos. In: GUIMARÃES-IOSIF, GUIMARÃES-IOSIF, R.; ZARDO, S. P.; SANTOS, A. V. dos (Orgs.). Educação Superior: conjunturas, políticas e perspectivas. Brasília: Líber Livro, 2015.

MARTINS, A. Carlos Pereira. Ensino Superior no Brasil: da descoberta aos dias atuais. 4 Acta Cirúrgica Brasileira - v. 17, (Suplemento 3), 2002.

MAUÉS, O. Formação e trabalho docente na educação superior. In: SILVA JÚNIOR, J. dos R.; SOUSA, J. V. de; AZEVEDO, M. L. N. de; CHAVES, V. L. J. (Orgs.). Educação Superior: Internacionalização, mercantilização e repercussões em um campo de disputas. Belo Horizonte, MG: Fino Traço, 2015.

MCCOWAN, T.; SCHENDEL, R. A mudança do papel da universidade e seu impacto na sociedade em países de baixa renda. In: SILVA JÚNIOR, J. dos R.; SOUSA, J. V. de; AZEVEDO, M. L. N. de; CHAVES, V. L. J. (Orgs.). Educação Superior: Internacionalização, mercantilização e repercussões em um campo de disputas. Belo Horizonte, MG: Fino Traço, 2015.

MOREIRA, A. F. B.; SILVA, T. T. da. Sociologia e teoria crítica do currículo: uma introdução. In: (Org.). Currículo, cultura e sociedade. São Paulo: Cortez, 2011.

ORO, M. C. P.; BASTOS, C. C. B. C. Formação Pedagógica para Docência Universitária: estudo das condições de cursos bacharelados de uma IES pública. Seminário de pesquisa em educação da região Sul, 2012.

PACHANE, G. G. Formação de Professores para a docência universitária no Brasil: uma introdução histórica. APRENDER - Cad. de Filosofia e Psic. da Educação. Vitória da Conquista, Ano VII, n. 12, p. 25-42, 2009.

PIMENTA, S. G.; ANASTASIOU, L. das G. C. Docência no Ensino Superior. São Paulo: Cortez, 2010. 
RECHE, B. D.; VASCONCELLOS, M. M. M. A construção da carreira docente por bacharéis: considerações iniciais. In: Seminário de Pesquisa em Educação da Região Sul. Reunião Científica Regional da ANPED, 2014, Florianópolis. Seminário de Pesquisa em Educação da Região Sul. Reunião Científica Regional da ANPED. Florianópolis: UDESC, 2014.

SACRISTÁN, J. O currículo: uma reflexão sobre a prática. 3. ed. Porto Alegre: Artes Médicas, 2000.

SILVA, L. E. das N.; GONZAGA, P. da C. Professor bacharel do ensino superior: formação, prática docente e professoralidade. Anais do III CONEDU - Congresso Nacional de Educação, ISSN 2358-8829, v. 1, 2016,

SILVA, T. T. da. Documentos de identidade: uma introdução às teorias do currículo. Belo Horizonte: Autêntica, 2011.

SOUSA, J. V. de. Educação superior no Distrito Federal: consensos, conflitos e transformações na configuração de um campo. Brasília: Faculdade de Educação/Universidade de Brasília; Liber Livro, 2013.

SUANNO, M. V. R. Docência universitária e didática emergente: novos caminhos para interrogar a realidade e redimensionar as experiências educativas. In: GUIMARÃES-IOSIF, Ranilce; Zardo, Sinara Pollon; SANTOS, A. V. dos (Orgs.). Educação Superior: conjunturas, políticas e perspectivas. Brasília: Líber Livro, 2015.

TEIXEIRA, A. Educação no Brasil. 3. ed. Rio de Janeiro: UFRJ, 1999.

VEIGA, I. P. A. Educação superior: políticas educacionais, currículo e docência. Curitiba: CRV, 2016.

\section{Como citar este artigo:}

SILVA, Franciso Thiago. Currículo e docência de bacharéis na Educação Superior privada: desafios da prática pedagógica. Revista Ibero-Americana de Estudos em Educação, Araraquara, v. 14, n. 4, p. 2189-2204, out./dez., 2019. e-ISSN: 1982-5587. DOI: https://doi.org/10.21723/riaee.v14i4.10866

Data de Submissão: 03/01/2018

Revisões requeridas: 26/06/2018

Aceite em: 30/11/2019

Publicado em: 02/09/2019 